\title{
Cinema in extremis: notas sobre um silêncio estridente em $O$ homem urso
}

\section{Marcelo Carvalho da Silva}

\section{Resumo}

0 ambientalista Timothy Treadwell, protagonista do filme $O$ homem urso (Grizzly man, 2005) de Werner Herzog, filia-se à galeria dos grandes personagens herzoguianos. Treadwell foi morto por um urso pardo no Alasca, no outono de 2003. 0 único vestígio dessa morte - tema latente do filme - é uma gravação em áudio realizada por acaso pela própria câmera de vídeo de Treadwell. 0 grande interesse da sequência onde esse áudio está inserido reside na maneira como Herzog 0 elide. Tal elisão suscita questões sobre os limites da imagem (Serge Daney e André Bazin) e a imagem-cristal deleuziana. Afinal, até onde uma imagem pode ir (questão ética) e como deve ser realizada (questão estética)?

\section{Palavras-chave}

O homem urso. Herzog. Treadwell. Elisão sonora. Imagem-cristal.

\section{Marcelo Carvalho da Silva I} marcelocarvalho.0001@yahoo.com.br Doutorando em Comunicação pela Universidade Federal do Rio de Janeiro (UFRJ). Bolsista da CAPES - processo nº 10457-12-7.

\section{Introdução}

A vida do ambientalista americano Timothy

Treadwell teve - principalmente em sua última fase - muitas das características encontradas nos personagens do cineasta alemão Werner Herzog. Tanto que Herzog o tornou protagonista de $O$ homem urso (Grizzly man, 2005). Treadwell acampou por treze verões consecutivos em Katmai National Park and Preserve, no Alasca, com 0 intuito de observar os ursos pardos, sendo morto com sua namorada, Amie Huguenard, por um urso no outono de 2003. $O$ homem urso é o resultado de uma seleção realizada por Herzog das imagens gravadas por Treadwell em câmeras de vídeo, imagens da natureza e dele próprio, sempre em Katmai Park. Todo esse material original (cerca de cem horas gravadas) foi montado a posteriori por Herzog, que inseriu entrevistas com amigos e parentes de Treadwell.

Mas, uma sequência difere de todo 0 resto do filme, uma sequência-chave tanto para 0 homem urso, como também para uma discussão sobre 
as possibilidades (estéticas) da sonoridade no cinema ou (mais perturbador ainda) da elisão de um som no cinema - no caso, instalando-se no limite (ético) da apresentação ou não de uma determinada gravação. Trata-se do momento em que o próprio Herzog aparece na tela, a única vez em todo o filme, justamente para ouvir 0 áudio da gravação da morte de Treadwell e de sua namorada: não é apenas o som mais importante do filme, mas o elemento ao redor do qual giram todos os outros elementos. A maestria demonstrada por Herzog nessa sequência está na maneira como elide esse som. Um som que, apesar de não 0 ouvirmos, é a contrapartida de todos os elementos de 0 homem urso - o que inclui 0 próprio Treadwell, personagem herzoguiano ímpar que inspirou o tratamento que 0 cineasta alemão deu ao áudio com sua morte, daí a investigação que fazemos de sua personalidade. Recorreremos amiúde a Gilles Deleuze quanto à imagem-cristal e às formulações de André Bazin e Serge Daney para a questão da morte no cinema como um limite ético da imagem.

\section{Treadwell, personagem herzoguiano}

Ir à natureza, gravar imagens dela. Muitos já fizeram isso. Mas há algo de particular em Treadwell: afinal, o que fazia ele em Katmai? Seu trabalho não era artístico, documental, muito menos científico. Ele interferia sem constrangimentos no curso natural dos acontecimentos ao, por exemplo, facilitar a subida de salmões em direção às nascentes para que os ursos tivessem alimento suficiente. Treadwell via-se como um protetor dos ursos pardos, defendia-os; mas, do quê? Sua resposta era: "da caça ilegal", mas o filme nos informa que a caça em absoluto ameaçava a espécie na reserva. Considerava o lugar como um éden intocável. Era o protetor e 0 vingador do mundo natural contra uma ameaça que só ele percebia, disposto a enfrentar a administração do parque, as leis e os turistas. Era um ativista, mas de uma causa inexistente, autoimbuído de uma missão inútil, um conquistador sem vitórias a serem exaltadas. ${ }^{1}$ Talvez, sua sobrevivência verão após verão pudesse ser alçada a uma vitória (vivo entre os selvagens ursos pardos...), mas 0 desfecho lhe desfavorece. Seus diários (sabemos pelo relato de Herzog) o mostram cada vez mais afastado do mundo dos homens e mais próximo do mundo dos ursos: no filme, vemos Treadwell interpretar grafites inocentes feitos por turistas como ameaças veladas à sua integridade física. Treadwell travaria sua batalha contra a civilização.

Esse esboço de Treadwell é suficiente para que se perceba que Herzog encontrou um personagem herzoguiano na "vida real". É evidente a 
semelhança entre o "personagem" criado por Treadwell para si próprio frente à sua câmera e o "personagem" que Klaus Kinski criou para sua vida e que contaminou os personagens de Herzog, com 0 estímulo deste. Entre Herzog e Kinski houve um encontro, mais do que uma influência, ${ }^{2}$ e talvez pudéssemos dizer o mesmo entre Herzog e Treadwell: comentando as imagens com as imprecações de Treadwell contra a administração do parque, Herzog, sem nomeá-lo diretamente, diznos já ter visto aquela "loucura" antes em um set de filmagem, referindo-se, evidentemente, a Kinski.

Segundo Deleuze (1985), a obra de Herzog poderia ser lida a partir de dois polos. No primeiro deles, um personagem hipertrofiado concebe uma ação desmesurada, uma missão grande demais para ser cumprida, com o intuito de igualarse a um meio igualmente desproporcional. "A ação não é exigida pela situação, trata-se de um empreendimento louco, que nasce da cabeça de um iluminado, e que parece ser o único capaz de se igualar ao meio inteiro" (DELEUZE, 1985, p. 228). Esse meio desproporcional é a própria natureza como força opressora e onipresente, potência que deve ser desafiada, prestes a entrar em colisão com os desejos humanos, prestes a aniquilar a empresa humana, céu ameaçador (Nosferatu, o fantasma da noite - 1979); floresta equatorial (Aguirre, a cólera dos deuses - 1972, Fitzcarraldo - 1982, O sobrevivente - 2006); deserto (Fata morgana - 1970, Lektionen in finsternis - 1992). Os gregos tinham uma noção que expressava tal descomedimento que parece afetar os heróis herzoguianos: a hybris, isto é, o "cair em erro" por se deixar levar pelo excessivo e o desmesurado e ultrapassar seu métron. "A maior ofensa aos deuses é 'não pensar humanamente", afastando-se da sophrosyne, dos limites da ação humana, invejando, assim, as divindades: "0 Homem não deve, portanto, aspirar ao que está alto demais" (JAEGER, 2003, p. 210-211). Cometer a hybris, se deixar arrebatar a ponto de fustigar a ordem divina, política e natural, ultrajaria a própria condição humana. Em Herzog, o divino foi substituído pela ordenação da natureza, e 0 embate se daria entre as potências acionáveis da natureza e a vontade humana.

Treadwell é um personagem da galeria herzoguiana, onde seres amalucados e estranhos se colocam como empreendedores de uma missão, de saída, inútil e sem efetividade, fadados ao fracasso (o preço a ser pago). Por certo, isso não passou despercebido ao cineasta quando assistiu às fitas com 0 material bruto realizado pelo ambientalista a convite da Fundação Grizzly People. 0 passado de Treadwell pouco explica sua trajetória, nada além de uma inclinação pouco definida em direção à persona que se transformaria. Foi nadador e tentou ser ator sem muito sucesso. Cometeu pequenos delitos, tinha uma vida que flertava com a marginalidade. Seu amigo Warren Queeney conta no filme que, após 
quase morrer de overdose, Treadwell teria mudado sua concepção de vida, fantasiando sobre si próprio, criando um passado falso de que era um órfão nascido na Austrália, chegando a imitar 0 sotaque de uma região do outback australiano.

Treadwell sentia-se salvo do alcoolismo e da marginalidade em sua vida reinventada entre os ursos (seus depoimentos para a própria câmera transparecem isso), ungido por considerar-se apto ao trabalho além das possibilidades de uma pessoa comum: proteger a vida selvagem em Katmai sem nenhum recurso que não seu próprio afeto, convivendo ao lado dos animais, partilhando seu território de beleza monumental ciente dos riscos. Sem resultados científicos, nem causa consistente, restava-lhe a alegria de confrontar o mundo humano em uma cruzada. Mas é justamente a insanidade de conviver com ursos pardos selvagens como se estes pudessem corresponder as suas demonstrações de carinho é que torna sua aventura heróica a seus próprios olhos. Ele não cansa de dizer o quanto o que faz é perigoso, em como, de uma hora para outra, ele poderia ser atacado e devorado pelos ursos. Treadwell havia cometido a hybris, ultrapassado o limite entre a cultura e a selvageria, transposto a distância necessária entre homem e animal, uma falha apontada tanto por um indígena (que denuncia o "mal" que 0 ele teria causado aos animais ao invadir seu espaço) quanto pelas recomendações oficiais.

Mas a motivação última, propriamente metafísica de Treadwell, seu delírio, era o de proteger a natureza. E não bastaria apenas defendê-la, mas tornar-se natureza, tomar parte do espírito dela, sempre contrapondo-a à cultura humana, degradada e degradante, ou mesmo se levantando contra o sobre-humano (neste caso, colocando-se ainda mais próximo do sentido original de hybris). É assim que 0 vemos fazer imprecações contra Deus, questionando-o sobre o porquê de não chover no parque, o porquê de permitir, assim, 0 canibalismo entre os ursos, já que os salmões não poderiam subir o rio para a desova e para servir de alimento aos animais.

Ainda segundo Deleuze, haveria outro polo para os personagens de Herzog. "Não são mais 'conquistadores do inútil', mas seres inutilizáveis. Não são mais iluminados, mas débeis, idiotas. As paisagens diminuem ou se achatam, tornam-se tristes e mornas" (DELEUZE, 1985, p. 228): os anões que tomam o sanatório em Também os anões começaram pequenos (1970); os cegose-surdos de No país do silêncio e da escuridão (1971); Kaspar Hauser (1974) e o mundo dos homens "civilizados"; 0 debilitado Woyzeck (1979); a paisagem onde se move Nosferatu, of fantasma da noite (1979). Poderíamos acrescentar: é também o inverso da alegria pela comunhão com a natureza em $O$ homem urso, quando surge em Treadwell uma estranha impotência encarnada no comportamento involuído, na voz infantilizada, no tratamento que dá aos ursos como se estes fossem animais de estimação; ou, de maneira até mais contundente, na melancólica intuição, revelada em muitos momentos, de que acabaria morto pelos 
ursos. Então, a comunhão com o mundo natural se daria não como união eufórica e espiritual com a natureza, mas como uma linha ziguezagueante que claudica entre os animais, em um jogo de adivinhação sobre qual urso poderia matá-lo.

A "linha ziguezagueante" remete à questão do andarilho. Herzog conhece muito bem a situação daquele que caminha. Ele percorreu a pé a distância entre Munique e Paris em 1974 para encontrar/homenagear a historiadora do cinema Lotte Eisner, na época, à morte. "0 andarilho é sem defesa porque é aquele que começa a ser e continua sempre pequeno" (DELEUZE, 1985, p. 229). Caminhar é atravessar a linha que separa dois mundos. Treadwell era 0 andarilho entre o mundo dos homens e o mundo selvagem, 0 caminhante entre os ursos, que cada vez mais só se sentia realmente em plenitude no convívio com os animais, mesmo que seu último retorno - uma saída em falso causada por um desentendimento no aeroporto após mais uma temporada em Katmai Park - o tenha levado ao seu fim.

\section{Treadwell e 0 cristal}

Há no comportamento extremado do personagem Treadwell uma estrutura propriamente espelhar, onde identificamos uma complexa relação entre atuais e virtuais que nos levam a encontrar nele indícios da imagem-cristal deleuziana. Deleuze recorre em sua obra à distinção bergsoniana entre 0 "atual" e 0 "virtual", verdadeira chave de compreensão de seu pensamento (cf. ALLIEZ, 1996; LÉVY, 1996; ZOURABICHVILI, 2004). "PensamentoAcontecimento ou, através de Nietzsche e Bergson enfim reunidos, 'criação' de pensamento que procede por virtualização" (ALLIEZ, 1996, p. 12-13, grifo do autor). Mas, o que é um "atual" e um "virtual" e como se distinguem do "real" e do "possível"? 0 real é o imediatamente detectado, domínio onde os objetos podem ser claramente definidos. Mas o real necessita, para que ganhe existência efetiva, das inúmeras possibilidades de tornar-se: a existência do real, de "algo real", se dá na esfera do possível de si mesmo. 0 possível existe, é real, embora, ao contrário deste, não esteja concretizado. Um possível real realiza-se analogicamente, por semelhança: 0 objeto real "x" assemelha-se à possibilidade (realizada e irrealizada) que 0 antecede, que pré-condiciona sua realização. Só é possível o que é passível de se realizar, já que as possibilidades do objeto real "x" conteriam, em si, pré-formas fantasmáticas adequada a esse objeto real "x".

0 virtual não é simplesmente um possível. Ambos são reais, mas enquanto este é a pré-determinação do que virá a ser real e de alguma forma sua existência se dá em ato, a existência do virtual é pura potência de atualização. ${ }^{4}$ Não se opondo ao real, 0 virtual coloca em xeque a identidade 
do objeto "x", é um tornar-se outro, devir outro. 0 virtual é "nó de tendências ou de forças que acompanha uma situação, um acontecimento, um objeto ou uma entidade qualquer, e que chama um processo de resolução: a atualização" (LÉVY, 1996, p. 16). 0 processo de virtualização traz ao real um quantum de indeterminação, daí a atualização de virtuais jamais ser uma solução pré-determinada. A atualização de um virtual é um processo de criação. Muito mais do que realizar 0 que se apresentava como uma possibilidade a se concretizar num momento posterior segundo um contexto pré-determinado, a atualização de um virtual é "uma produção de qualidades novas, uma transformação das idéias, um verdadeiro devir que alimenta de volta o virtual" (LÉVY, 1996, p. 16-17).

Acontece que Deleuze identifica dois processos distintos de passagem entre 0 virtual e 0 atual, a atualização de virtuais e a cristalização do virtual e do atual numa mesma imagem, a imagem-cristal. Ambos os processos se inscrevem numa temporalidade. Na atualização de virtuais a diferenciação entre estes e 0 atual remete à distinção entre um presente que não cessa de transcorrer, precipitando-se no futuro, e um passado que se conserva como virtualidade pura (BERGSON, 1990). Segundo Deleuze (1985), encontramos essa relação no cinema da imagem-movimento, notadamente nos filmes de ação: cada elemento, personagem, contexto, objeto, temporalidade etc., é localizável segundo coordenadas histórico-geográficas e/ou psicológicas sempre atuais. Sabemos algo sobre o personagem, inferimos qual a sua classe, seu país, quais seus gostos, e cada virada psicológica em seu percurso é atribuída a uma causa evidente ou escamoteada, por vezes soterrada no passado do personagem como virtualidade. A recordação (atualização) destas causas - que comporão a malha de explicações e justificativas das ações tomadas - se dá pelo flashback, justamente, 0 recurso por excelência da atualização de um virtual: as lembranças apresentam-se na tela como um "passado presentificado" e todas as outras lembranças possíveis, recalcadas, continuam virtuais, prontas para serem acionadas, remetendo o esforço de lembrar a circuitos cada vez mais alargados.

Algo de outra ordem acontece no processo de cristalização. Em vez de uma imagem virtual - uma lembrança, por exemplo - que, ao atualizar-se, substitui a antiga imagem, tornando-se 0 novo atual, temos uma imagem onde não há substituição, mas uma co-habitação, uma coalescência espelhar entre 0 atual e 0 virtual na mesma imagem. Já não há mais identidade fixa do personagem, nem representação possível. Tal indiscernibilidade leva a um indecidível inerente a esta imagem bifacial (qual 0 atual e qual 0 virtual?). Atual e virtual, embora distintos, estão numa situação de indiscernibilidade, numa intercambialidade constante que os fazem constantemente trocar de papéis. "Há também coalescência e cisão, ou antes oscilação, perpétua troca entre 0 objeto atual e sua imagem virtual: a imagem virtual não pára de tornar-se atual, como num espelho [...]" 
(DELEUZE, 1996, p. 53-54). Não há mais flashbacks psicológicos, mas um mergulho direto no tempo onde passado e presente se entrelaçam num jogo de fluxos que minam as identidades, como em $O$ ano passado em Marienbad (1961, de Alain Resnais e Alain Robbe-Grillet). Afinal, em Marienbad, estamos no passado com o personagem do homem ou no presente com a mulher? Não adianta o esforço para descobrir a chave secreta do filme, pois o passado-virtual e o presente-atual trocam de posição constantemente, compondo tal imagem bifacial, a imagem-cristal da imagemtempo. A imagem-cristal é o menor circuito, limite interior entre um virtual e um atual, germe cristalino que se desenvolve até alcançar o último circuito, o universo como meio cristalizável e expansão no tempo.

A imagem-cristal tem estes dois aspectos: limite interior de todos os circuitos relativos, mas também invólucro último, variável, deformável, nos confins do mundo, para além dos movimentos do mundo. 0 pequeno germe cristalino e 0 imenso universo cristalizável: tudo está compreendido na capacidade de amplificação do conjunto constituído pelo germe e pelo universo (DELEUZE, 1990, p. 101-102).

0 personagem Treadwell atravessaria os polos opostos da galeria de personagens de Herzog, compondo para si uma imagem-cristal. Por um lado, é como o apequenado que se dá a redenção de Treadwell: se 0 seu grande projeto metafísico malogra - tanto pela morte por um urso, quanto pelo desaparecimento do "único" humano capaz de comungar com a natureza de seu interior -, sua impotência o faz vitorioso. É no papel de involuído e débil, do ambientalista romântico e sentimental que chora como uma criança ao ver sua visão ingênua da natureza ser questionada pela própria natureza, que Treadwell pôde aproximar-se do sublime ${ }^{5}$, galgando novamente a dimensão do agigantado em meio a uma desmesura. Ecoando outros filmes de Herzog (como No país no silêncio e da escuridão), também em $O$ homem urso o tato desempenha fator fundamental neste sentido: chegar bem próximo, sentir 0 arfar do animal, tocar seu pêlo, ou mesmo colocar a mão em seu excremento ainda quente são as supremas sensações a serem conquistadas. Tocar o animal, "tornando-se" natureza, é o equivalente sensorial ao êxtase visionário e místico, seu ritual metafísico.

[...] os debilitados [...] têm tais relações de tato com o mundo que inflam e inspiram a própria imagem [...]. E esta liberação dos valores táteis não se contenta em inspirar a imagem, entreabrindo-a e nela introduzindo amplas visões alucinatórias de vôo, de ascensão ou de travessia (DELEUZE, 1985, p. 230).

Referimo-nos a Kant, especificamente à Crítica da faculdade do juízo. 0 sublime é o que causa concomitantemente prazer e dor (desconforto psíquico) em um estado geral de desordem das faculdades pela presença sensível de algo de desmesura em seu aspecto formal (uma montanha que esmaga nosso espírito; a potência de uma tempestade que nos fascina e nos desestabiliza) que excederia tanto nossa intuição sensorial, quanto nosso entendimento (cf. KANT, 2002). 
Nesse vai e vem entre o pequeno e 0 agigantado, entre 0 conquistador do inútil e uma louca hipertrofia que o conduz invariavelmente a uma celebração das forças da natureza das quais jamais se afasta, é que se constitui a primeira grande imagem-cristal de $O$ homem urso. 0 jogo espelhar é vertiginoso na medida em que o que se apresentava como desmesura, passa rapidamente a uma dimensão débil, para desta, alcançar 0 êxtase e 0 sublime. As passagens não são localizáveis, constituem dimensões indiscerníveis, e coabitam o mesmo plano, fala, gesto, a ponto de perguntarmos: afinal, o que vejo através dessa imagem-cristal é o Treadwell proponente de uma missão de desmesura ou aquele que sobrevive sob o peso de sua própria debilidade?

\section{Inocência do primeiro}

Em O homem urso, um determinado som tem importância fundamental. Todo o filme gira em torno de um único plano sonoro que, no entanto, a despeito de seu caráter central, jamais ouvimos. Quando Treadwell e sua namorada são atacados pelo urso, a câmera está ligada. Não temos a imagem - a lente da câmera estava tampada -, mas o som do ataque foi gravado (seis minutos ao todo). 0 filme como o conhecemos só existe porque Treadwell teve tal morte e, se 0 momento teve um registro, qualquer que fosse este registro, ele deveria "estar presente" no filme de alguma forma. Mas, como incluir esse som? De que forma fazê-lo presente - se é, per si, incontornável - tendo registrado o que registrou, o momento terrível do ataque? Há necessidade de se ouvir a gravação, pois faz parte do filme mais do que qualquer outro som ou imagem, mas ela possui a marca do registro maldito, da audição insuportável. Seria preciso encontrar uma forma de necessariamente incluir essa gravação no filme "sem que esteja" concretamente presente. 0 dilema é estético e ético.

0 problema repercute um tema bastante trabalhado por alguns dos grandes teóricos e críticos do cinema: afinal, haveria um limite que não se poderia ultrapassar, uma região interditada ao cinema? A questão adquire importância fundamental para a crítica francesa da segunda metade do século XX - com o crítico André Bazin (1990) como elo fundamental-, ressaltando 0 paradoxo entre a reprodutibilidade da exibição de um filme e a morte como fato único. Esses autores, de uma forma ou de outra, invocam a morte como o ponto limite para a imagem do cinema.

$$
\begin{aligned}
& \text { A reprodução infinita daquilo que é único ao ser } \\
& \text { que morre constitui a negação extrema do campo } \\
& \text { ético, definindo a obscenidade. Esse é o grande } \\
& \text { movimento que encontramos nos fundamentos } \\
& \text { da ética baziniana e na normatividade estilística } \\
& \text { realista que promove (RAMOS, 2005, p. 220). }
\end{aligned}
$$

Escrevendo sobre Kapo (1960), filme de Gillo Pontecorvo, Jacques Rivette cria uma expressão que ganha notoriedade, 0 "travelling de Kapo", onde procura determinar o limite para a constituição de uma imagem. Sua argumentação 
incide sobre um pequeno travelling no filme de Pontecorvo tido como abjeto por ser "estetizante", quando a situação - a morte de alguém - exigiria sobriedade formal. 0 travelling descrito por Rivette mostra o momento em que a prisioneira de um campo de concentração nazista, Emanuelle Riva, suicida-se, jogando-se contra uma cerca de arame-farpado eletrificada. A abjeção a qual Rivette faz menção não está em mostrar a morte violenta da personagem, mas no fato de Pontecorvo realizar o movimento de câmera - associado a um leve contra-plongée - com 0 intuito de tornar o plano formalmente mais belo de uma maneira gratuita (RIVETTE, 1961). Haveria, enfim, determinados procedimentos fílmicos que não deveriam se constituir se a intenção for puramente formal, devendo guardar-se na irrealização frente à morte filmada.

Bem mais tarde, já nos anos 1990, Serge Daney retoma 0 texto de Rivette, reconsiderando tal interdição em seu artigo 0 travelling de Kapo. Daney (1994, p. 28, tradução nossa) diferencia 0 tratamento que o cineasta japonês Kenji Mizoguchi dá à morte de Miyagi em Contos da lua vaga (1953) e o travelling de Pontecorvo em Kapo com a morte de Emanuelle Riva: "então, onde está a diferença? Exatamente, 'no temor e no tremor'. [...] Pontecorvo, não teme, nem crê: os campos de concentração só o revoltam ideologicamente. É por este motivo que ele acrescenta um 'a mais' na cena, um belo e inútil travelling”. ${ }^{6} 0$ tema volta em outros momentos de Daney, direta ou indiretamente (DANEY, 2004, 2007). 0 problema do tratamento formal revela que o nó a ser enfrentado é o da atualização da morte como ato cinematográfico.

É na verdade a presença da morte no cinema que está em questão, atestando novamente a filiação, apesar dos deslocamentos e rupturas, de Daney a Bazin. A morte como 0 acontecimento por excelência que problematiza e redimensiona os limites da filmagem (Daney) e da montagem (Bazin) e o que pode qualificar um travelling como uma questão de moral, assim como também defenderam Rivette e Godard. 0 cinema, segundo Daney, pode ensinar uma lição à primeira vista simples: 0 mundo existe e torna-se moral na medida em que não deve ser mostrado de qualquer maneira, ideia que vai ao encontro da noção baziniana de montagem proibida (LINS; FRANÇA, 1999, p. 181-182).

Daney é um crítico pós-campos de concentração nazistas: "a" ignomínia, ou a superação dessa ignomínia (tanto para ele, quanto para toda uma geração de críticos), está fortemente associada à questão das imagens que se referem aos campos - como continuar produzindo imagens após 0 horror, de que forma se poderia continuar fazendo cinema? A resposta a tal "presente" insustentável veio com o cinema moderno. Dois filmes se 
destacam por oposição na análise de Daney (1994, p. 23, tradução nossa): Kapo (a referência de Daney para este filme é 0 artigo de Rivette) e Noite e neblina (Nuit et brouillard, 1955), de Alain Resnais, até então, o filme por excelência sobre o tema pela sobriedade como aborda a questão. "Poderia ter sido de outra forma?", perguntase Daney. "Haveria, diante dos campos de concentração, uma outra justeza possível que não aquela do anti-espetáculo de Nuit et brouillard?".? Responde a si próprio citando outro filme, $\mathrm{Nazi}$ concentration camps (1945), documentário realizado pelo cineasta George Stevens, então acompanhando as tropas dos EUA durante 0 avanço sobre a Alemanha.

0 que eu compreendo hoje é que a beleza do filme de Stevens encontra-se menos no fato de uma justeza na distância estabelecida do que na do olhar de quem vê. A justeza é o ônus daquele que chega 'mais tarde'; a inocência, a graça terrível concedida ao primeiro que chega. Ao primeiro que simplesmente cumpre os gestos da filmagem (DANEY, 1994, p. 24, tradução nossa). ${ }^{8}$

Aquele que conquistou o direito de ter vindo primeiro e aquele que carrega o ônus de ter chegado depois...
É curioso surpreender Herzog retomando essa questão - logo Herzog, tantas vezes criticado por sua falta de limites para conseguir uma imagem. Treadwell veio primeiro, e seu olhar e escuta inocentes, sobre a natureza, seu quixotismo, 0 exime de um julgamento quanto às suas imagens $\mathrm{e}$ quanto ao som de sua própria morte, até pelo fato de que certamente sua câmera de vídeo (a mesma câmera que tantas vezes antes captou Treadwell em performances próprias a um programa televisivo) estava ligada acidentalmente no momento fatídico. É Herzog, aquele que veio depois com seu olhar de observador/montador exterior à cena, que precisa se perguntar sobre a justeza de incluir ou não 0 som com o momento fatal de Treadwell e sua namorada, sobre "como" esse olhar e, principalmente, essa escuta inocentes farão parte do filme. É ele quem deve se perguntar sobre a "impossibilidade de narrar", como diz Daney (1994, p. 25, tradução nossa) referindo-se à Noite e neblina: "[...] a honestidade de conscientizar-se de uma mesma impossibilidade de relatar, de uma mesma suspensão frente ao decorrer da História, quando a narrativa se fixa ou se acondiciona no vácuo". ${ }^{9}$

0 que está em causa em 0 homem urso não é a inclusão de um adorno estetizante, mas uma

"Pouvait-il en être autrement ?" [...] "Y avait-il, face aux camps, une autre justesse possible que celle de l'anti-spectacle de Nuit et brouillard?"

"Ce que je comprends aujourd'hui, c'est que la beauté du film de Stevens est moins le fait de la justesse de la distance trouvée que de l'innocence du regard porté. La justesse est le fardeau de celui qui vient 'après' ; l'innocence , la grâce terrible accordée au premier venu. Au premier qui exécute simplement les gestes du cinema".

“[...] l'honnêteté de prendre acte d'une même impossibilité de raconter, d'un même cran d'arrêt dans le déroulé de l'Histoire, quand le récit se fige ou s'emballe à vide". 
revelação insuportável: como montar esse áudio no filme e, ao mesmo tempo, como não incluir indevida e violentamente 0 espectador em um lugar onde ele não deveria estar? No filme Diário do homem urso o próprio Herzog diz que ficou claro para ele, após ouvir o áudio da gravação, que este não deveria constar materialmente do filme por uma questão de dignidade e privacidade ("só por cima do meu cadáver essa fita seria incluída"), que se deveria respeitar o momento da morte de uma pessoa, "da sua morte, da minha e da de Treadwell e Huguenard". E retornamos à questão, que não é a da morte propriamente dita, mas a da morte nas imagens produzidas, da morte exposta em papel fotográfico, frame ou película: como tratá-la, como dotar tal imagem de uma marca diferente da marca que os vivos imprimem comumente nas imagens, uma marca "de silêncio" como a que dá consistência ao protocolar "minuto de silêncio"? Como, ao fazermos imagens, sermos dignos de quem morre na imagem que se produz? A questão atravessa a história das imagens produzidas no século XX: de Bazin a Rivette e a Daney; da fotografia $A$ morte de um militante, de Robert Capa, à polêmica sobre como o holocausto dos judeus nos campos de concentração nazistas deveria ser tratado, polêmica que capturou o filme Shoah (1985), de Claude Lanzmann, como um exemplo de tratamento ideal do tema (mais um) ao não fazer uso das imagens de arquivo dos campos filme tido como irretocável, pois se recusou a tocar em tais imagens. Herzog demonstra ter se colocado problemas semelhantes em $O$ homem urso. A solução encontrada, de caráter ético-estético, se dá por duas elisões simultâneas, de imagem e de som.
A sequência-chave, de construção formal bastante simples, localiza-se quase na metade do filme, como a dividi-lo em duas partes proporcionais. Vemos Herzog enquadrado de costas; seu rosto não aparece (elisão visual), apenas sua nuca e parte do ombro direito no canto esquerdo da tela; está com fones de ouvido, de cabeça baixa. Ao fundo, ocupando a parte direita do quadro, vemos a amiga e ex-namorada de Treadwell, Jewel Palovak, de frente para Herzog, sentada com a câmera do ambientalista no colo. Estão em uma sala, ouve-se 0 som baixo do bater das ondas do mar. A câmera faz um zoom-in na imagem, buscando enquadrar Jewel. Apenas Herzog ouve a gravação (elisão sonora: 0 som da morte de Treadwell e Huguenard) e a comenta de maneira vacilante, enquanto o rosto de Jewel, ao fundo, está imóvel, expressando perplexidade. A câmera faz uma pequena panorâmica, deixando Jewel e reenquadrando novamente a nuca de Herzog, que leva à mão aos olhos aparentando estar em estado de choque (seu corpo parece tremer) - esse enquadramento (que continua a elisão visual anterior) leva alguns segundos. Após um corte, o novo plano retorna ao quadro inicial do plano passado; Herzog pede que Jewel desligue a câmera. Novo silêncio; somente Jewel, que começa a chorar, pode ver o rosto do diretor. A câmera faz um leve zoom-in (que permanecerá durante todo esse plano) e Herzog pede a ela que jamais ouça a gravação, ou veja as fotos dos corpos. Ela concorda. Herzog aparenta estar ainda profundamente chocado. Novo corte, os dois estão de mãos dadas, como que em um apoio mútuo e 
Jewel diz que agora ele sabe o porquê de ninguém poder ouvir esta gravação. Herzog, por fim, devolve a fita, pedindo a ela que a destrua. Ela concorda. A sequência acaba com um fade-out, o único de toda a película além daquele que termina o filme e dofade-in que inicia a projeção. Toda a sequência (que dura exatamente um minuto e 52 segundos) é crua, sóbria. Não há, aqui, nenhum vestígio de um "travelling de Kapo".

\section{Conclusão}

Alguém precisaria ouvir a gravação elidida e Herzog poupa o espectador ao se colocar em "sacrifício". Esse som é o que há de mais próximo da imagem que falta ao filme, a imagem não gravada do encontro fatal de Treadwell com o urso: sua audição solitária, de costas, procura nos dar conta não só do som que não ouvimos, como também das imagens que não foram registradas, por meio de uma substituição elegíaca visual. 0 material registrado parece ser de tal modo insuportável que precisamos de uma imagem que nos faça aguentar a própria imagem de Herzog ouvindo o áudio do ataque. Vemos, então, o rosto de Jewel ao fundo tentando suportar o que presume que Herzog esteja sentindo ao ouvir a gravação: 0 rosto de Jewel ao mesmo tempo elide e reflete 0 horror que provavelmente está estampado no rosto de Herzog para que suportemos o insuportável. Há uma triangulação nesta sequência que envolve som e imagem de maneira visceral: só Herzog ouve o horror; Jewel
0 vê ouvindo e se emociona ao imaginar o que ele ouve; nós a vemos chorar e ela chora por nós, em nosso lugar, pois é quem teve a relação mais íntima com Treadwell, é quem tem mais direito de lamentar 0 ocorrido. Por um lado, o tratamento formal dado à sequência nos alivia sensorialmente, pois somos inseridos no interior da questão central do filme - a morte violenta de Treadwell e Huguenard - por um duplo rebatimento (de Herzog para Jewel, desta para o espectador) pelo qual compreendemos a carga insuportável que aquela fita carrega ("jamais escute isso"; "não deve guardá-la, deveria destruíla" diz Herzog a Jewel). No entanto, a imagem continua portando o som elidido. Vemos o horror que aquele som poderia causar-nos, vemos o som em seu jogo espelhar com a imagem que existe (Herzog ouve a fita com a expressão de Jewel ao fundo) e a que não existe (da morte do casal pelo urso). Se um esquema sensório-motor, próprio à imagem-movimento (DELEUZE, 1985), ${ }^{10}$ pareceria neutralizar a potência dessa gravação ao substituíla pela imagem de Herzog e Jewel, o jogo espelhar instaurado na imagem não nos deixa esquecer quão terrível ela é. A elisão sonora, mesmo que sirva para Herzog pôr um limite moral para seu cinema, acaba por afirmar a força desse som em sua dimensão virtual, mas plenamente real.

Assim é porque o som elidido, virtualizado, materialmente ausente, se faz presente de uma forma avassaladora, a ponto de não mais ser possível distinguir entre sua ausência ou presença. 
Como vimos, é quando um efeito espelhar de reflexos entre 0 atual 0 o virtual - ambos distintos, mas indiscerníveis - os lança em um jogo constante de troca de papéis é que surge uma imagem-cristal, imagem de natureza bifacial (DELEUZE, 1990, p. 87120). 0 atual e 0 virtual se rebatem constantemente na imagem-cristal: onde está o horror, no áudio virtual que não ouvimos, ou em sua atualização presente no filme como nenhum outro elemento - na imagem, nos sucessivos rebatimentos entre 0 som e a imagem? As reações (atualizações) que vemos no rosto de Jewel pertencem a quem: a ela própria ou trata-se de um reflexo das reações irradiadas virtualmente pelo rosto de Herzog, rosto que apenas Jewel vê, sendo Herzog o único a ouvir a gravação? Se a construção formal dos rebatimentos acaba por evocar um esquema sensório-motor de atenuação da violência, como anteriormente referido, a presença imaterial desse som como instância indiscernível de virtualidade/atualidade (no jogo entre 0 som elidido, a imagem de Herzog que escuta a fita e o rosto de Jewel ao fundo) nos dá a segunda grande imagemcristal na coalescência entre imagem e som, na indiscernibilidade atual/virtual suscitada.

A imagem-cristal composta pela saga do personagem Treadwell, oscilando entre 0 apequenamento e a desmesura, no limite impreciso entre 0 atual e 0 virtual, é o leitmotiv do filme, fresta para a crueza do mundo natural, suas imagens, seus sons, seu estridente silêncio contido numa fita de vídeo. Mas é na sequencia do som elidido que encontramos o circuito atual/ virtual mais estreito que espelha formalmente a própria oscilação do personagem. Por certo, 0 tratamento formal dado a esta sequência reflete uma escolha de Herzog de cunho moral. Uma escolha que (conjecturando) poderia ter sido outra em sua juventude e que pertence unicamente à relação entre Herzog e (a morte de) Treadwell. Tal construção formal, o cuidado estético demonstrado por Herzog na elaboração da elisão do som da morte de Treadwell e Huguenard, resulta na exposição clara dos limites do próprio Herzog. Para além de se afirmar uma interdição moral generalizada, cabenos constatar que há limites que definem o que é e o que não é suportável nas imagens em geral, mas são limites cambiantes, conjunturais, históricos - a despeito do nosso eventual horror quando somos afrontados por parâmetros que nos constrangem, sejam do público ou do cineasta.

\section{Referências}

ALLIEZ, Éric. Deleuze filosofia virtual. Rio de Janeiro: Ed. 34, 1996.

BAZIN, André. 0 cinema. São Paulo: Brasiliense, 1990. BERGSON, Henri. Matéria e memória. São Paulo: Matins Fontes, 1990.

DANEY, Serge. A rampa - Cahiers du Cinéma, 19701982. São Paulo: Cosac Naify, 2007. Cine, arte del presente. Buenos Aires: Santiago Arcos editor, 2004. Le travelling de Kapo. In:

Persévérance: Entretien avec Serge Toubiana. Paris: Éditions P.O.L., 1994.

DELEUZE, Gilles. A imagem-movimento. São Paulo: Brasiliense, 1985. 
A imagem-tempo. São Paulo: Brasiliense, 1990.

0 atual e 0 virtual. In: ALLIEZ, Eric. Deleuze

filosofia virtual. Rio de Janeiro: Editora 34, 1996.

DIÁRIO do homem urso (The grizzly man diaries). Direção: Erik Nelson. Produção: Jason Carey, Erik Nelson e Jewel Palovak. Elenco: Timothy Treadwell, Amie Huguenard, Werner Herzog, Jewel Palovak e Warren Queeney. EUA: [S.n.], 2008. Emissão televisiva, cor.

HERZOG, Werner. Caminhando no gelo. Rio de Janeiro: Paz e Terra, 1982.

0 HOMEM urso (Grizzly man). Direção e roteiro: Werner Herzog. Produção executiva: Kevin Beggs. Elenco: Timothy Treadwell, Amie Huguenard, Werner Herzog, Jewel Palovak e Warren Queeney. Música original: Richard Thompson.

EUA, Alemanha: [S.n.], 2005. (94min.), cor.

JAEGER, Werner. Paidéia: a formação do homem grego. São Paulo: Martins Fontes, 2003.

KANT, Immanuel. Crítica da faculdade do juízo. Rio de Janeiro: Forense Universitária, 2002.

KAPO. Direção: Gillo Pontecorvo. Roteiro: Gillo Pontecorvo e Franco Solinas. Produção: Fanco Cristaldi e Moris Ergas. Elenco: Susan Strasberg, Laurent Terzieff e Emmanuelle Riva. Música original: Carlo Rustichelli. Itália: [S.n.], 1960. (116 min.), widescreen. LALANDE, André. Vocabulário técnico e crítico da filosofia. São Paulo: Martins Fontes, 1999.

LINS, Consuelo; GERVEISAU, Henri; FRANÇA, Andrea. 0 cinema como abertura para o mundo: introdução ao pensamento de Serge Daney. Revista Cinemais, n. 15, p. 171, jan./fev. 1999.

LÉVY, Pierre. 0 que é o virtual? São Paulo: Editora 34, 1996.

NAZI concentration camps. Direção: George Stevens. EUA: [S.n.], 1945. (59min.)
NOITE e neblina (Nuit et brouillard). Direção: Alain Resnais. Produção: Anatole Dauman, Samy Halfon e Philippe Lifchitz. Roteiro: Jean Cayrol (com edição de texto de Chris Marker). Narração: Michel Bouquet. Música original: Hanns Eisler. França: [S.n.], 1955.

(32min.), cor.

RAM0S, Fernão Pessoa. A cicatriz da tomada: documentário, ética e imagem-intensa. In: Teoria

Contemporânea do Cinema: documentário e narratividade ficcional. São Paulo: Editora SENAC São Paulo, 2005. v. II.

RIVETTE, Jacques. De l'abjection. Cahiers du Cinéma, n.120, p. 54-55, jun. 1961.

ZOURABICHVILI, François. Una filosofia del acontecimiento. Buenos Aires: Amorrortu, 2004. 


\section{Cinema in extremis: notes on an strident silence in the film Grizzly man}

\section{Cine in extremis: notas sobre un silencio estridente en $\mathrm{EI}$ hombre oso}

\section{Abstract}

The environmentalist Timothy Treadwell, protagonist of the film Grizzly Man (2005) by Werner Herzog, joins the filmmaker's gallery of great characters. Treadwell was killed by a grizzly bear in Alaska in the fall of 2003. The only evidence of his death - a latent subject of the film - is an audio tape recorded by accident by Treadwell's video camera. The great interest of the sequence that presents this audio tape consists in how Herzog elides the sound. Such elision raises questions about the limits of image (Serge Daney and André Bazin) and Deleuze's crystal-image. How far can image go (an ethical question) and how should it be realized (an esthetic question)?

\section{Keywords}

Grizzly man. Herzog. Treadwell. Sound elision. Crystal-image.

\section{Resumen}

El ambientalista Timothy Treadwell, protagonista de la película El hombre oso (Grizzly man, 2005) de Werner Herzog, se junta a la galería de los grandes personajes herzoguianos. Treadwell fue víctima de un oso pardo en Alaska, en el otoño de 2003. El único vestigio de esa muerte - tema latente de la película - es una grabación en audio hecha por casualidad por la propia cámara de video de Treadwell. El gran interés de la secuencia donde ese audio está inserido reside en la manera como Herzog lo elide. Tal elisión suscita cuestiones sobre los límites de la imagen (Serge Daney y André Bazin) y la imagen-cristal deleuziana. Al final, לhasta qué punto puede ir una imagen (cuestión ética) y cómo debe llevarse a cabo (cuestión estética)?

\section{Palabras claves}

El hombre oso. Herzog. Treadwell. Elisión sonora. Imagen-cristal. 


\section{Expediente}

A revista E-Compós é a publicação científica em formato eletrônico da Associação Nacional dos Programas de Pós-Graduação em Comunicação (Compós). Lançada em 2004, tem como principal finalidade difundir a produção acadêmica de pesquisadores da área de Comunicação, inseridos em instituições do Brasil e do exterior.
E-COMPÓS I www.e-compos.org.br I E-ISSN 1808-2599

Revista da Associação Nacional dos Programas

de Pós-Graduação em Comunicação.

E-compós, Brasilia, v.15, n.3, set./dez. 2012.

A identificação das edições, a partir de 2008

passa a ser volume anual com três números.

\section{CONSELHO EDITORIAL}

Afonso Albuquerque, Universidade Federal Fluminense, Brasil Alberto Carlos Augusto Klein, Universidade Estadual de Londrina, Brasil Álvaro Larangeira, Universidade Tuiuti do Paraná, Brasil André Luiz Martins Lemos, Universidade Federal da Bahia, Brasil Ângela Freire Prysthon, Universidade Federal de Pernambuco, Brasil Angela Cristina Salgueiro Marques, Faculdade Cásper Líbero (São Paulo), Brasil Antonio Roberto Chiachiri Filho, Faculdade Cásper Líbero, Brasil Arthur Autran Franco de Sá Neto, Universidade Federal de São Carlos, Brasi Benjamim Picado, Universidade Federal Fluminense, Brasil César Geraldo Guimarães, Universidade Federal de Minas Gerais, Brasil Cristiane Freitas Gutfreind, Pontifícia Universidade Católica do Rio Grande do Sul, Brasil

Denilson Lopes, Universidade Federal do Rio de Janeiro, Brasil Eduardo Peñuela Cañizal, Universidade Paulista, Brasil Eduardo Vicente, Universidade de São Paulo, Brasil Eneus Trindade, Universidade de São Paulo, Brasil Erick Felinto de Oliveira, Universidade do Estado do Rio de Janeiro, Brasil Florence Dravet, Universidade Católica de Brasília, Brasil Gelson Santana, Universidade Anhembi/Morumbi, Brasil Gislene da Silva, Universidade Federal de Santa Catarina, Brasil Guillermo Orozco Gómez, Universidad de Guadalajara Gustavo Daudt Fischer, Universidade do Vale do Rio dos Sinos, Brasil Hector Ospina, Universidad de Manizales, Colômbia Herom Vargas, Universidade Municipal de São Caetano do Sul, Brasil Inês Vitorino, Universidade Federal do Ceará, Brasil Jay David Bolter, Georgia Institute of Technology Jeder Silveira Janotti Junior, Universidade Federal de Pernambuco, Brasil John DH Downing, University of Texas at Austin, Estados Unidos José Afonso da Silva Junior, Universidade Federal de Pernambuco, Brasil José Carlos Rodrigues, Pontifícia Universidade Católica do Rio de Janeiro, Brasil José Luiz Aidar Prado, Pontifícia Universidade Católica de São Paulo, Brasil Kelly Cristina de Souza Prudêncio, Universidade Federal do Paraná, Brasil.
Laan Mendes Barros, Universidade Metodista de São Paulo, Brasil Lance Strate, Fordham University, USA, Estados Unidos Lorraine Leu, University of Bristol, Grã-Bretanha Lucia Leão, Pontifícia Universidade Católica de São Paulo, Brasil Malena Segura Contrera, Universidade Paulista, Brasil

Márcio de Vasconcellos Serelle, Pontifícia Universidade Católica de Minas Gerais, Brasil

Maria Aparecida Baccega, Universidade de São Paulo e Escola Superior de Propaganda e Marketing, Brasil

Maria Ataide Malcher, Universidade Federal do Pará, Brasil

Maria das Graças Pinto Coelho, Universidade Federal do Rio Grande do Norte, Brasil Maria Immacolata Vassallo de Lopes, Universidade de São Paulo, Brasil Maria Luiza Martins de Mendonça, Universidade Federal de Goiás, Brasil Mauro de Souza Ventura, Universidade Estadual Paulista, Brasil Mauro Pereira Porto, Tulane University, Estados Unidos Mirna Feitoza Pereira, Universidade Federal do Amazonas, Brasil Nilda Aparecida Jacks, Universidade Federal do Rio Grande do Sul, Brasil Osvando J. de Morais, Universidade de Sorocaba, Brasil Potiguara Mendes Silveira Jr, Universidade Federal de Juiz de Fora, Brasil Renato Cordeiro Gomes, Pontifícia Universidade Católica do Rio de Janeiro, Brasil Robert K Logan, University of Toronto, Canadá

Ronaldo George Helal, Universidade do Estado do Rio de Janeiro, Brasil Rose Melo Rocha, Escola Superior de Propaganda e Marketing, Brasil Rossana Reguillo, Instituto de Estudos Superiores do Ocidente, Mexico Rousiley Celi Moreira Maia, Universidade Federal de Minas Gerais, Brasil Sebastião Guilherme Albano da Costa, Universidade Federal do Rio Grande do Norte, Brasil

Simone Maria Andrade Pereira de Sá, Universidade Federal Fluminense, Brasil Tiago Quiroga Fausto Neto, Universidade de Brasília, Brasil Suzete Venturelli, Universidade de Brasília, Brasil Valerio Fuenzalida Fernández, Puc-Chile, Chile

Veneza Mayora Ronsini, Universidade Federal de Santa Maria, Brasil Vera Regina Veiga França, Universidade Federal de Minas Gerais, Brasil

\section{COMISSÃO EDITORIAL}

Adriana Braga I Pontifícia Universidade Católica do Rio de Janeiro, Brasil Felipe Costa Trotta I Universidade Federal Fluminense, Brasil

\section{CONSULTORES AD HOC}

Ana Carolina Escosteguy, Pontifícia Universidade Católica do Rio Grande do Sul, Brasil Bruno Campanella, Universidade Federal Fluminense, Brasil

Edison Gastaldo, Universidade Federal Rural do Rio de Janeiro, Brasil Elizabeth Duarte, Universidade Federal de Santa Maria, Brasil Roseli Figaro, Universidade de São Paulo, Brasil

EDIÇÃO DE TEXTO E RESUMOS I Susane Barros

SECRETÁRIA EXECUTIVA I Juliana Depiné

EDITORAÇÃo ELETRÔNICA I Roka Estúdio

TRADUÇÃO I Sieni Campos e Markus Hediger
COMPÓS I www.compos.org.br

Associação Nacional dos Programas de Pós-Graduação em Comunicação

Presidente

Julio Pinto

Pontifícia Universidade Católica de Minas Gerais, Brasil juliopinto@pucminas.br

Vice-presidente

Itania Maria Mota Gomes

Universidade Federal da Bahia, Brasil

itania@ufba.br

Secretária-Geral

Inês Vitorino

Universidade Federal do Ceará, Brasil

inesvic@gmail.com 